Review Article

\title{
Effects of Cognitive Behavioral Therapy on Pain and Sleep in Adults with Traumatic Brain Injury: A Systematic Review and Meta-Analysis
}

\author{
Xin Li $\mathbb{D}^{1,2}$ Yuwei Feng, ${ }^{1}$ Jianping Xia, ${ }^{3}$ Xuan Zhou, ${ }^{1}$ Nan Chen, ${ }^{1,4}$ Zhengquan Chen $\mathbb{D}^{1}$ \\ Qimeng Fan, ${ }^{1}$ Hong Wang ${ }^{\circ},{ }^{5}$ Peiyuan Ding ${ }^{\circ},{ }^{6}$ and Qing Du $\mathbb{( i )}^{1}$ \\ ${ }^{1}$ Department of Rehabilitation, Xinhua Hospital, School of Medicine, Shanghai Jiaotong University, Shanghai 200092, China \\ ${ }^{2}$ School of Kinesiology, Shanghai University of Sport, Shanghai 200438, China \\ ${ }^{3}$ Department of Rehabilitation, Maternity \& Child Care Center of Xinyu, Xinyu, 338000 Jiangxi, China \\ ${ }^{4}$ Department of Rehabilitation, Chongming Branch of Xinhua Hospital, School of Medicine, Shanghai Jiaotong University, \\ Shanghai 202150, China \\ ${ }^{5}$ College of Rehabilitation Science, Shanghai University of Medicine \& Health Sciences, Shanghai 201318, China \\ ${ }^{6}$ Department of Neurosurgery, Chongming Branch of Xinhua Hospital, School of Medicine, Shanghai Jiaotong University, \\ Shanghai 202150, China
}

Correspondence should be addressed to Hong Wang; wanghongplus@163.com, Peiyuan Ding; 13564338032@163.com, and Qing Du; duqing@xinhuamed.com.cn

Received 27 May 2021; Revised 29 August 2021; Accepted 27 September 2021; Published 11 November 2021

Academic Editor: Jia-Bao Guo

Copyright (C) 2021 Xin Li et al. This is an open access article distributed under the Creative Commons Attribution License, which permits unrestricted use, distribution, and reproduction in any medium, provided the original work is properly cited.

The objective of this study was to systematically review the literature on the effects of cognitive behavioral therapy (CBT) on insomnia and pain in patients with traumatic brain injury (TBI). PubMed, Embase, the Cochrane Library, Cumulative Index to Nursing and Allied Health, and Web of Science databases were searched. Outcomes, including pain, sleep quality, and adverse events, were investigated. Differences were expressed using mean differences (MDs) with 95\% confidence intervals (CIs). The statistical analysis was performed using STATA 16.0. Twelve trials with 476 TBI patients were included. The included studies did not indicate a positive effect of CBT on pain. Significant improvements were shown for self-reported sleep quality, reported with the Pittsburgh Self-Reported Sleep Quality Index (MD, $-2.30 ; 95 \%$ CI, -3.45 to $-1.15 ; P<0.001$ ) and Insomnia Severity Index (MD, $-5.12 ; 95 \% \mathrm{CI},-9.69$ to $-0.55 ; P=0.028)$. No major adverse events related to CBT were reported. The underpowered evidence suggested that CBT is effective in the management of sleep quality and pain in TBI adults. Future studies with larger samples are recommended to determine significance. This trial is registered with PROSPERO registration number CRD42019147266.

\section{Introduction}

Traumatic brain injury (TBI) is a global public health and medical priority with an annual incidence estimated at 200 1967 per 100,000 of the population [1]. The agestandardized prevalence of TBI increased by $8.4 \%$ from 1990 to 2016 globally $[2,3]$, and it became the third leading cause of death and disability [4]. Regardless of the extent, both acute and more chronic consequences that lead to permanent behavioral disabilities and pain associated with most
TBIs are due to diffuse axonal injury [5]. Approximately $65 \%$ of patients who survive moderate-to-severe TBI subsequently suffer from a wide range of symptoms ranging from physical disabilities (pain, fatigue, etc.) to psychological impairments (hypomnesia, depression, anxiety, etc.) [6], which reduces life expectancy and presents a substantial economic burden to victims, their families, and society as a whole [7].

Pain is reported in over $50 \%$ of TBI patients [8], with approximately $20 \%$ of TBI patients developing possible 
neuropathic pain and sleep problems [9]. In most cases, pain is associated with other post-TBI complaints [10], such as sleep disturbance, which represents a vital interventional target, although sleep disorders and pain are sometimes two independent and separately occurring symptoms of TBI. To enhance interventional efficacy, particularly for TBI patients who have severe pain [11], cognitive behavioral therapies should target both sleep and pain due to the negative effect of pain on sleep quality.

Strong evidence has shown that cognitive behavioral therapy (CBT) is beneficial for the nonbrain-injured population that has cognitive impairments, such as those with anxiety, depression, or intellectual disabilities [12, 13], or for the population with acquired brain injuries, such as those who experienced cerebral vascular accident, anoxia, and neurosurgery [14]. The mechanisms underpinning these improvements appear to be that CBT helps TBI patients understand how to identify and change disturbing thought patterns that have a negative influence on behavior and emotions through a psychotherapeutic approach $[15,16]$. Therefore, CBT is an alternative option for patients who suffer from pain and are not suitable for drug therapy. The evidence suggests that CBT, as one of the neuropsychological interventions that combines cognitive and behavioral techniques [17], is the "gold standard" treatment for pain-related symptoms in those with a wide range of musculoskeletal or neurological diseases [18]. However, there has been conjecture that CBT is also effective in post-TBI pain (headache or widespread pain). Moreover, CBT has also been recommended as a first-line treatment for other pain-related dysfunctions (such as sleep disorders and neuropathic pain) [19], although no quantitative meta-analysis has been performed to investigate the effects of CBT on sleep quality in adults with TBI. The present systematic review with meta-analysis is therefore aimed at examining the evidence for the effectiveness of CBT programs on pain and sleep quality in patients with TBI.

\section{Methods}

2.1. Literature Search and Selection Criteria. This metaanalysis was planned, conducted, and reported in adherence with the Preferred Reporting Items for Systematic Review and Meta-Analysis (PRISMA) statement [20]. Using search terms such as "traumatic brain injury", "TBI", "cognitive behavio(u)r therapy*", "CBT", "pain" and "sleep", we searched PubMed, Embase, the Cochrane Library, Cumulative Index of Nursing and Allied Health Literature (CINAHL), and Web of Science for English-language parallel-group studies reporting the effect of CBT in TBI patients published up to July 2021. The search strategies are shown in Appendix S1. Two reviewers (Peiyuan D and Qing D) independently performed the systematic literature search, detected and deleted all duplicate records, screened the titles, and identified abstracts based on relevance. The full-text articles designated for inclusion were reviewed. In addition, the reference lists of the retrieved articles and available review articles were manually checked to identify additional eligible studies.
Studies were selected for detailed review if they fulfilled the following population, intervention, comparison, outcome, and study design (PICOs) framework: (1) population: TBI participants who had brain damage due to external forces (such as direct impact, rapid acceleration or deceleration, a penetrating injury, or blast waves from an explosion) or a subgroup with TBI whose data could be extracted by the authors, with no restrictions on age, sex, or ethnicity (regular medication use was allowed); (2) intervention: any treatment classified as CBT; (3) comparison: no treatment or non-CBT (including pharmacotherapy); and (4) outcomes: primary outcomes were pain (measured by visual analog scales, the McGill Pain Questionnaire (MPQ), a pain diary, or pressure pain thresholds), sleep quality (assessed by the self-reported Pittsburgh Sleep Quality Index (PSQI), and adverse events associated with $\mathrm{CBT}$, which were reported as the number of participants experiencing any adverse event, number of participants who withdrew because of adverse events, and number of participants experiencing any serious adverse event. Data from randomized controlled trials (RCTs) and case studies were extracted, while only data from RCTs were synthesized.

2.2. Data Extraction and Quality Assessment. Data were extracted by Xin L using a customized data extraction form and independently confirmed by another reviewer (Yuwei F). Detailed information was extracted from each study, including first author, year of publication, study design, number of participants (\% women), and demographic and outcome data. Detailed descriptions of the CBT intervention and control group in these RCTs were collected. When the same patients were reported in several publications, we retained only the publication with the largest sample size to avoid duplication of information. Discrepancies were resolved through discussion with a third reviewer (Jianping $\mathrm{X})$ to reach a consensus. The Cochrane risk of bias tool [21] was used to assess the methodological quality of the included studies.

2.3. Statistical Analysis and Data Synthesis. Statistical analysis was performed using STATA, version 16.0. In the quantitative data synthesis section, a random effects model was chosen if two or more trials evaluated the same outcome in comparable groups with the mean difference (MD) and 95\% confidence interval (CI) calculated for the summary statistics. If two or more control groups received various treatments in one trial, we combined the data from the control groups using the formula recommended by the Cochrane Handbook for Systematic Reviews of Interventions [21]. The median, interquartile range, and sample size of each trial were obtained to estimate the mean and variance for each study using simple and elementary inequalities and approximations if necessary [22]. The $I^{2}$ statistic was calculated to assess heterogeneity among studies, with values $<25 \%$ indicating no heterogeneity, $25 \%$ to $50 \%$ indicating low heterogeneity, $50 \%$ to $75 \%$ indicating moderate heterogeneity, and $>75 \%$ indicating high heterogeneity.

The potential publication bias was visually assessed by drawing a funnel plot. Additionally, corresponding authors 
were contacted to provide details on unreported data, which was required for our meta-analysis. The Grading of Recommendations Assessment, Development, and Evaluation (GRADE) system was applied to specify the quality of each outcome by categorizing studies into four levels (high, moderate, low, and very low) by accessing the following factors: study design, study limitations (risk of bias), inconsistency, indirectness of study results, imprecision, and publication bias [23] (shown in Appendix S2).

\section{Results}

3.1. Study Identification and Selection. The initial electronic search returned a total of 737 records, with 619 unique records identified after duplicates were excluded. A total of 566 titles and abstracts were excluded for various reasons (i.e., they were reviews, letters, or irrelevant to the analysis). Of the remaining 53 articles, 6 RCTs and 6 case studies covering 476 patients were included based on the inclusion criteria. Figure 1 shows the PRISMA flow diagram of the studies in this review.

3.2. Study Characteristics. The demographic and baseline clinical variables of the included studies are shown in Table 1. Studies included both sexes, the mean age of the subjects in the study ranged from 11 to 72 years, and the number of participants in the CBT group ranged from 1 to 200. All studies analyzed in this review included individuals with TBI. Table 2 summarizes the detailed CBT methods in the intervention groups in the RCTs and case studies and the interventional methods in the control groups in the RCTs. Overall, the study duration lasted from 4 weeks to 1 year, with a median of 8 weeks and 4 to 12 sessions. The standard CBT protocol was mentioned in 3 RCTs [24-26] and 1 case study [27], while cognitive behavioral therapy for insomnia (CBT-I) was used in 1 RCT [28] and 4 case studies [29-32]. Two RCTs [33, 34] and 1 case series [35] implemented a CBT-based integrated intervention. An education intervention [26], a wait-list control condition [24, 25], or treatment as usual $[28,33,34]$ was conducted in the control groups.

3.3. Quality Assessment. The assessment of the risk of bias for the included RCTs is shown in Table 3. All RCTs reported the numbers and reasons for withdrawal or dropout. Five of the included RCTs generated an adequately randomized sequence $[24,26,28,33,34]$, and three were conducted in a blinded fashion for the outcome assessment $[28,33,34]$. Given that the pooled number of trials in this comparison was quite small (maximum of 3 trials), no funnel plot analysis was performed.

\subsection{Outcome Measurements}

\subsubsection{Primary Outcomes}

(1) Pain. While pain is the main symptom after TBI and has a great impact on quality of life, only 4 RCTs and 3 case studies screened the severity of pain in various forms [24, $25,33,34]$. Nguyen et al. [34] mentioned that the Brief Pain
Inventory data of their participants were obtained at baseline; however, the Brief Pain Inventory was not assessed after the intervention. One of the RCTs used the MPQ [25] to quantify the severity of pain before and after the intervention and found no significant changes after the CBT intervention. Pressure pain thresholds and data from a headache diary were employed as outcome measures in Kjeldgaard and colleague's study, and there was no significant reduction in pain [24]. Moreover, the other RCT [33] used headache pain items from the Traumatic Brain Injury-Quality of Life questionnaire, and no significant improvement in pain was found. Because the three included RCTs $[24,25,33]$ had a high degree of heterogeneity in the pain measurements, a meta-analysis of data may have been unconvincing.

In two of the case studies [27, 35], qualitative measures, such as the intensity and frequency of headache and medication use, were recorded at baseline and after a long-term follow-up (from 36 weeks to over one year), and significant improvements were found in the characteristics of the headaches, and much fewer pain killers were used. The Brief Pain Inventory was also used in the study of Lu et al.; however, the effects of CBT on the Brief Pain Inventory scores were contradictory [31].

(2) Sleep Quality. Sleep quality was assessed in 4 RCTs [26, $28,33,34$ ] and 4 case studies [29-32]. The PSQI is a selfreported questionnaire that demonstrates good psychometric properties for measuring sleep quality and impairment in various populations $[26,28,34]$. The pooled analysis across three studies $[26,28,34]$ showed a significant improvement in self-reported sleep quality in the CBT group (MD, $-2.30 ; 95 \% \mathrm{CI},-3.45$ to $-1.15 ; P<0.001)$. The heterogeneity among studies was acceptable $\left(\chi^{2}=0.49, P=0.783\right.$, $I^{2}=0 \%$ ) (Figure 2). The Insomnia Severity Index was used in Nguyen et al.'s [34] and Tomfohr-Madsen et al.'s study [28], and the pooled analysis showed that insomnia was significantly improved in the CBT group (MD, -5.12 ; 95\% CI, -9.69 to $-0.55 ; P=0.028)$, but the heterogeneity among studies was high $\left(\chi^{2}=6.31, P=0.012, I^{2}=84.2 \%\right)$ (Figure 3 ). Actigraphy, a validated objective test of sleep quality [36] used in Theadom et al.'s study [26], evaluates sleep onset, time awake, and the number of awakenings. However, there were no significant differences in the actigraphy measures after 6 weeks of a CBT-based online intervention. Additionally, in the two RCTs that recruited adolescents $[28,33]$, positive changes were also found in other sleep quality measures, such as the Dysfunctional Beliefs and Attitudes about Sleep Scale, a sleep diary, and the Adolescent Sleep Wake Scale.

The Insomnia Severity Index was used in all 4 case studies [29-32], and most of the participants showed a negative trend in the Insomnia Severity Index scores, which indicated improvements in insomnia, although the decrease in insomnia severity was not clinically significant in the study of $\mathrm{Lu}$ et al. [31]. Sleep diaries were another useful tool for recording daily sleep habits, and quantified data from sleep diaries, 


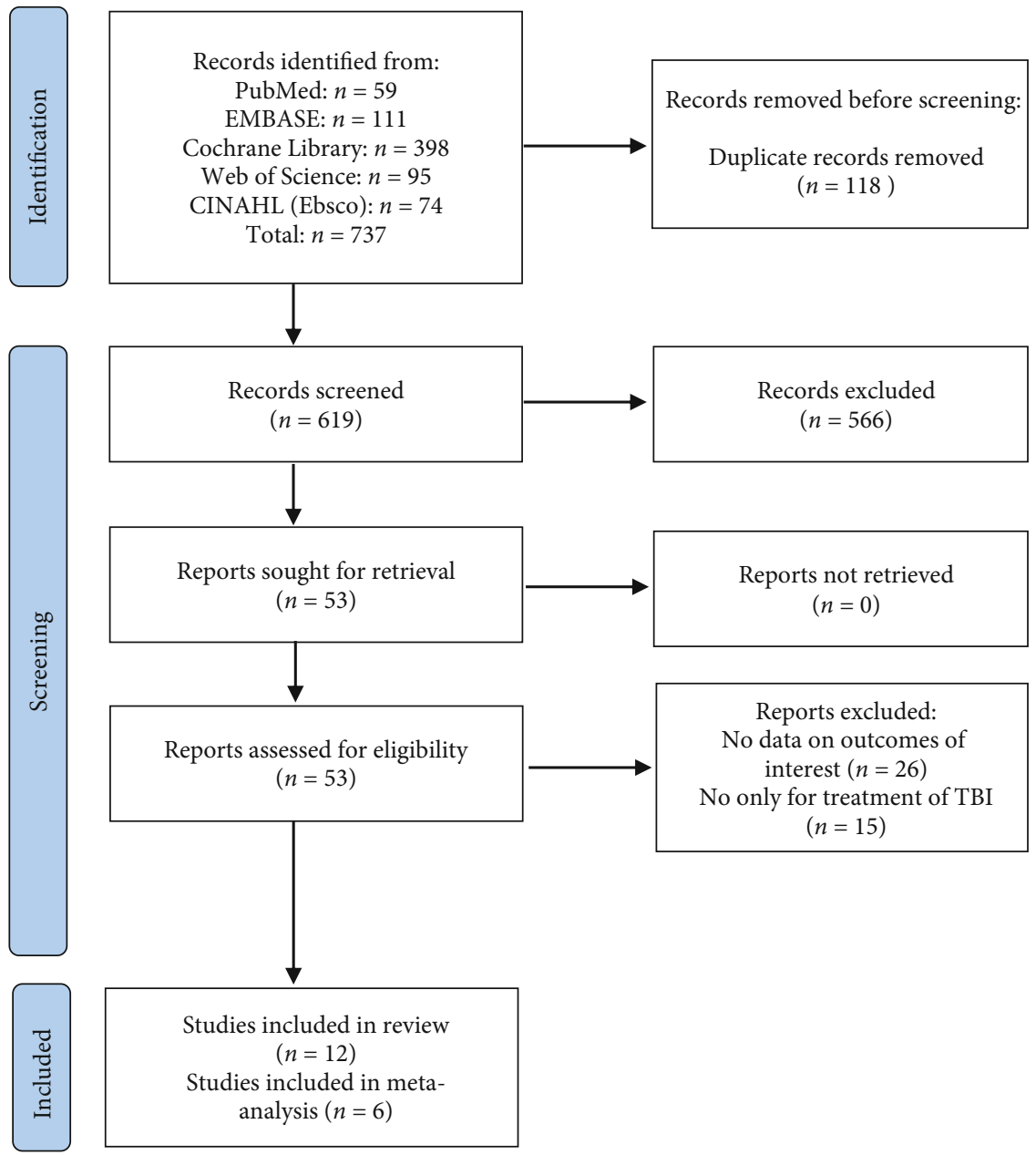

Figure 1: PRISMA flow diagram of studies in this review.

such as total sleep time and sleep efficiency, showed positive changes in the TBI participants with sleep disturbances in the 4 case studies [29-32].

(3) Adverse Events. CBT was well tolerated among the participants in most included studies. An average of 5.3 participants withdrew during the CBT intervention, and the overall dropout rate was $7.8 \%$ in the 6 included RCTs, mainly due to loss to follow-up or active withdrawal. Furthermore, no major adverse events, such as progression of symptoms, suicide, or death, were reported among the participants during the CBT intervention.

\section{Discussion}

The primary purpose of this meta-analysis was to examine the relative efficacy between CBT treatments and non-CBT treatments for TBI. The principal finding of this systematic review and meta-analysis of TBI was that CBT is associated with a significant improvement in self-reported sleep quality but not pain, and CBT was found to be well tolerated among these patients.

Due to the heterogeneity in pain evaluation methods across studies, a meta-analysis could not be performed, although the general trend of the results on pain was described. The TBI patients in the CBT groups did not have significant changes in pain or headache measured by questionnaires or a hand-held pressure algometer after the entire intervention in the included RCTs [24, 25, 33]. Contrary to the expectations that CBT would have marked efficacy on pain, even slight changes could not be discriminated considering the placebo effect of CBT. The reason for the lack of significance may be that most of the included patients suffered from long-term TBI sequelae, and the pain experience in the TBI patients may be profound and chronic. A neuroimaging study showed that chronic pain would remodel sensorimotor activation in the gray matter of the brain, such as widespread alterations in somatosensory cortices, supplementary motor areas, and superior temporal gyri [37]. It is estimated that if CBT or pain education is employed in the early stage after brain trauma, pain symptoms may not enter the chronic stage [24], while pharmacological therapy seems more effective in chronic pain [38]. In contrast to the results from the RCTs, a decrease in the intensity and frequency of headache was found in the two case studies [27, 35]. The mechanisms of the effects of CBT on pain relief lie in changing thoughts as they relate to pain and improving pain through behavioral reinforcement. These improvements 


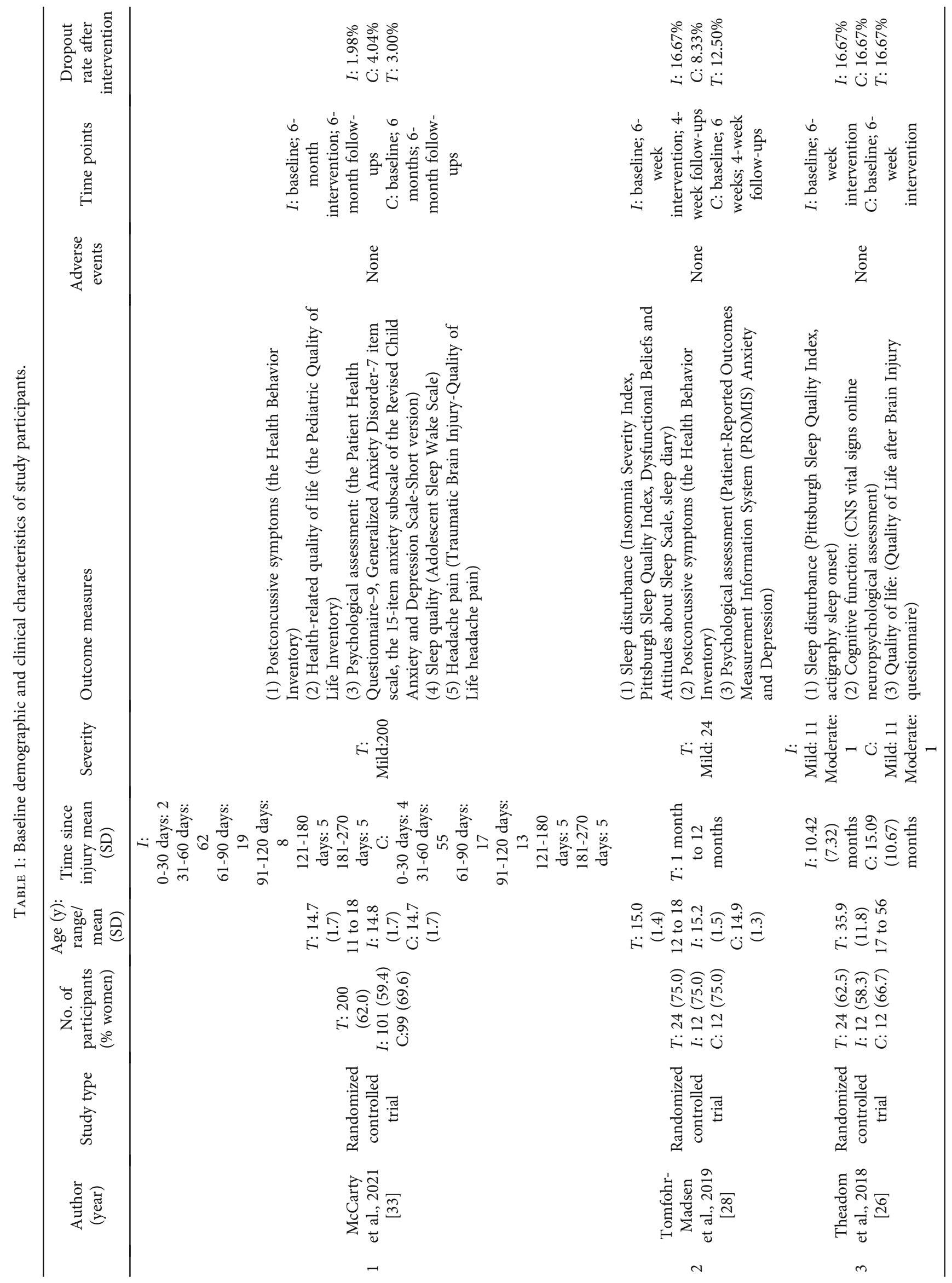




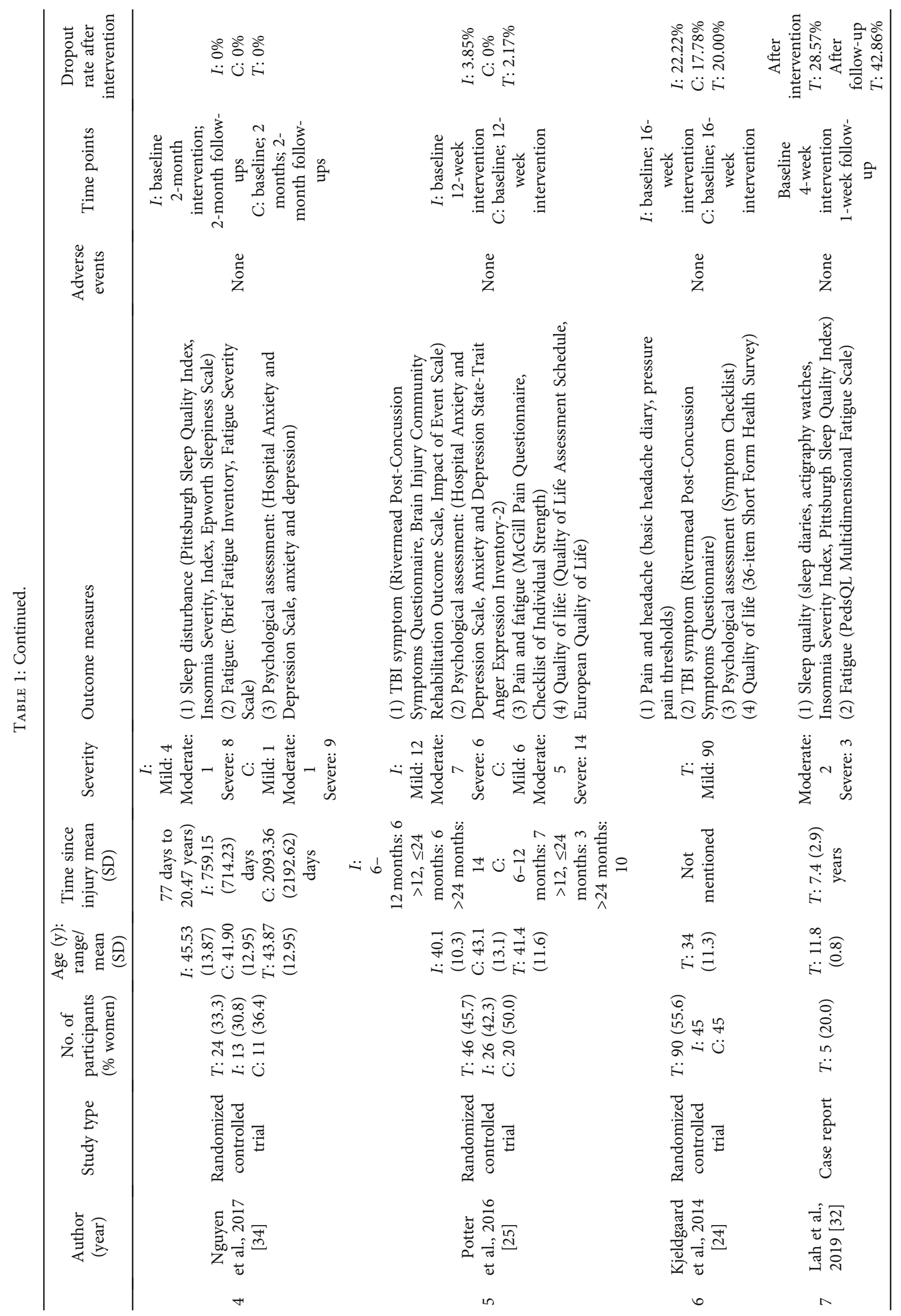




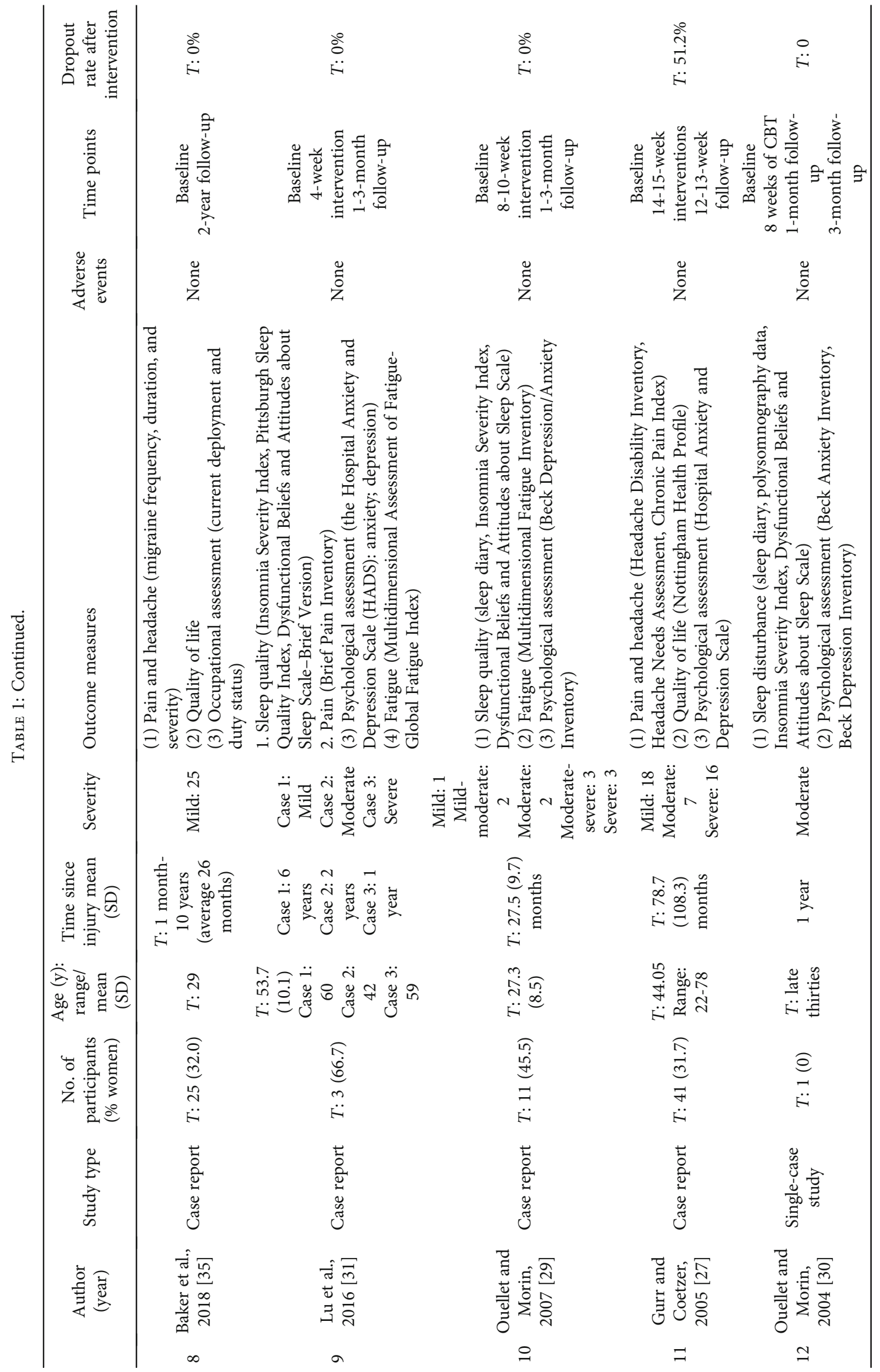


TABLE 2: Cognitive behavioral therapy and control interventions in the included parallel-group trials.

\begin{tabular}{|c|c|c|c|c|c|}
\hline & Author (year) & $\begin{array}{l}\text { Cognitive behavioral therapy in the } \\
\text { intervention group }\end{array}$ & $\begin{array}{l}\text { Control group } \\
\text { intervention }\end{array}$ & Frequency & Duration \\
\hline 1 & McCarty et al., 2021 [33] & $\begin{array}{l}\text { Hybrid (telehealth and face-to-face) } \\
\text { individualized intervention with care } \\
\text { management and enhanced } \\
\text { medication consultation }\end{array}$ & Usual health care & 1 hour per week & 6 months \\
\hline 2 & $\begin{array}{l}\text { Tomfohr-Madsen et al., } \\
\text { 2019 [28] }\end{array}$ & $\begin{array}{l}\text { Insomnia-specified individualized } \\
\text { intervention }\end{array}$ & Usual health care & 45 minutes per week & 6 weeks \\
\hline 3 & Theadom et al., 2018 [26] & $\begin{array}{l}\text { Online individualized intervention } \\
\text { with interactive features or } \\
\text { suggestions on behavior change }\end{array}$ & $\begin{array}{l}\text { Online education } \\
\text { without interactive } \\
\text { features or suggestions } \\
\text { on behavior change }\end{array}$ & 20 minutes per week & 6 weeks \\
\hline 4 & Nguyen et al., 2017 [34] & $\begin{array}{l}\text { Face-to-face individualized } \\
\text { intervention with } 30 \text {-minute exercise }\end{array}$ & Usual health care & $\begin{array}{l}\text { Moderate exercise } 30 \text { minutes } 3 \\
\text { to } 5 \text { times per week \& cognitive } \\
\text { behavioral therapy } 1 \text { session } \\
\text { per week }\end{array}$ & 2 months \\
\hline 5 & Potter et al., 2016 [25] & $\begin{array}{l}\text { Face-to-face individualized } \\
\text { intervention }\end{array}$ & Waiting list control & 1 hour per week & 12 weeks \\
\hline 6 & $\begin{array}{l}\text { Kjeldgaard et al., } \\
2014[24]\end{array}$ & Face-to-face group intervention & Waiting list control & 2 hours per week & 9 weeks \\
\hline 7 & Lah et al., 2019 [32] & $\begin{array}{l}\text { Face-to-face insomnia-specified } \\
\text { individualized intervention }\end{array}$ & I & 75 minutes per week & 4 weeks \\
\hline 8 & Baker et al. 2018 [35] & $\begin{array}{c}\text { Face-to-face individualized } \\
\text { intervention with lifestyle } \\
\text { modifications }\end{array}$ & l & Not mention & 2 years \\
\hline 9 & Lu et al., 2016 [31] & $\begin{array}{l}\text { Insomnia-specified individualized } \\
\text { intervention }\end{array}$ & l & 1 hour per week & 4 weeks \\
\hline 10 & $\begin{array}{l}\text { Ouellet and Morin, } \\
2007 \text { [29] }\end{array}$ & $\begin{array}{l}\text { Face-to-face insomnia-specified } \\
\text { individualized intervention }\end{array}$ & l & 1 hour per week & $\begin{array}{c}8-9 \\
\text { weeks }\end{array}$ \\
\hline 11 & $\begin{array}{l}\text { Gurr and Coetzer, } \\
2005 \text { [27] }\end{array}$ & $\begin{array}{c}\text { Face-to-face group relaxation \& face- } \\
\text { to-face individualized therapy } \\
\text { session }\end{array}$ & l & $\begin{array}{l}\text { Group intervention per week } \\
\text { for } 3 \text { weeks \& individualized } \\
\text { intervention } 30 \text { mins per two } \\
\text { weeks for } 12 \text { weeks }\end{array}$ & $\begin{array}{l}14-15 \\
\text { weeks }\end{array}$ \\
\hline 12 & $\begin{array}{l}\text { Ouellet and Morin, } \\
2004[30]\end{array}$ & $\begin{array}{l}\text { Face-to-face insomnia-specified } \\
\text { individualized intervention }\end{array}$ & l & 1 session per week & 8 weeks \\
\hline
\end{tabular}

require long-term CBT treatment. The CBT interventions in the case studies lasted for a long time, and the main intervention target was headache, so there was a positive intervention effect. Sleep disorders, which might be associated with diffuse axonal injury resulting in damage to sleep-regulating structures and disruptions in hypocretin-1, can be categorized: insomnia was found in $29 \%$, hypersomnia in $28 \%$, and sleep apnea in $25 \%$ of patients who have a history of TBI [39]. Sleep has a significant impact on the quality of life of TBI patients, and sleep disturbances have been consistently related to anxiety, depression, fatigue, or other complications. Many studies have reported that PSQI scores are associated with subjective questionnaire scores for anxiety and depression [40-42]. Although evidence on CBT specific to patients with TBI was scarce, our meta-analysis found a significant improvement in self-reported sleep quality measured with the PSQI, which was in accordance with the results of Ouellet MC's study [43]. However, there were no significant changes in actigraphy measures. Sleep quality is more like a subjective experience, and CBT could subjectively change participants' thoughts in relation to sleep and improve sleep behavior. As a result, self-reported sleep quality rose, and the objective data (actigraphy measures) may not improve as much as the subjective measures. Greater heterogeneity appeared in the data synthesis of the Insomnia Severity Index. In the two included RCTs, there were great difference characteristics of the participants, as female adolescents accounted for $75 \%$ of the participants in Tomfohr-Madsen et al.'s study [28], while the age span of the participants in Nguyen et al.'s study [34] was large. However, the biggest contributor to the heterogeneity was from the difference in baseline symptoms of insomnia. Insomnia in the participants in Tomfohr Madsen et al.'s study [28] was more severe than that in Nguyen et al.'s study [34], and CBT is known to achieve larger effect sizes in groups with more severe insomnia. To a certain extent, our results were partially contrary to Ford et al.'s conclusion that there was a reliable effect in support of CBT for TBI patients with sleep disorders [44]. Several methodological differences may be proposed to explain the contrasting findings. Whereas 
TABLe 3: The Cochrane Collaboration's tool for assessing risk of bias for methodological assessment.

\begin{tabular}{|c|c|c|c|c|c|c|c|}
\hline Article (year) & $\begin{array}{c}\text { Random } \\
\text { sequence } \\
\text { generation }\end{array}$ & $\begin{array}{c}\text { Allocation } \\
\text { concealment }\end{array}$ & $\begin{array}{l}\text { Blinding of } \\
\text { participants and } \\
\text { personnel }\end{array}$ & $\begin{array}{l}\text { Blinding of } \\
\text { outcome } \\
\text { assessments }\end{array}$ & $\begin{array}{c}\text { Incomplete } \\
\text { outcome } \\
\text { data }\end{array}$ & $\begin{array}{l}\text { Selective } \\
\text { reporting }\end{array}$ & $\begin{array}{l}\text { Other } \\
\text { bias }\end{array}$ \\
\hline McCarty et al., 2021 & Low & Unclear & High & Low & Low & High & Unclear \\
\hline Tomfohr-Madsen et al., 2019 & Low & Unclear & High & Low & High & Low & Unclear \\
\hline Theadom et al., 2017 [26] & Low & Low & Unclear & Unclear & High & Low & Unclear \\
\hline Nguyen et al., 2017 [34] & Low & Unclear & High & Low & Low & Low & Unclear \\
\hline Potter et al., 2016 [25] & Unclear & Unclear & High & High & Low & High & Unclear \\
\hline Kjeldgaard et al., 2014 [24] & Low & Low & High & High & High & High & Unclear \\
\hline
\end{tabular}

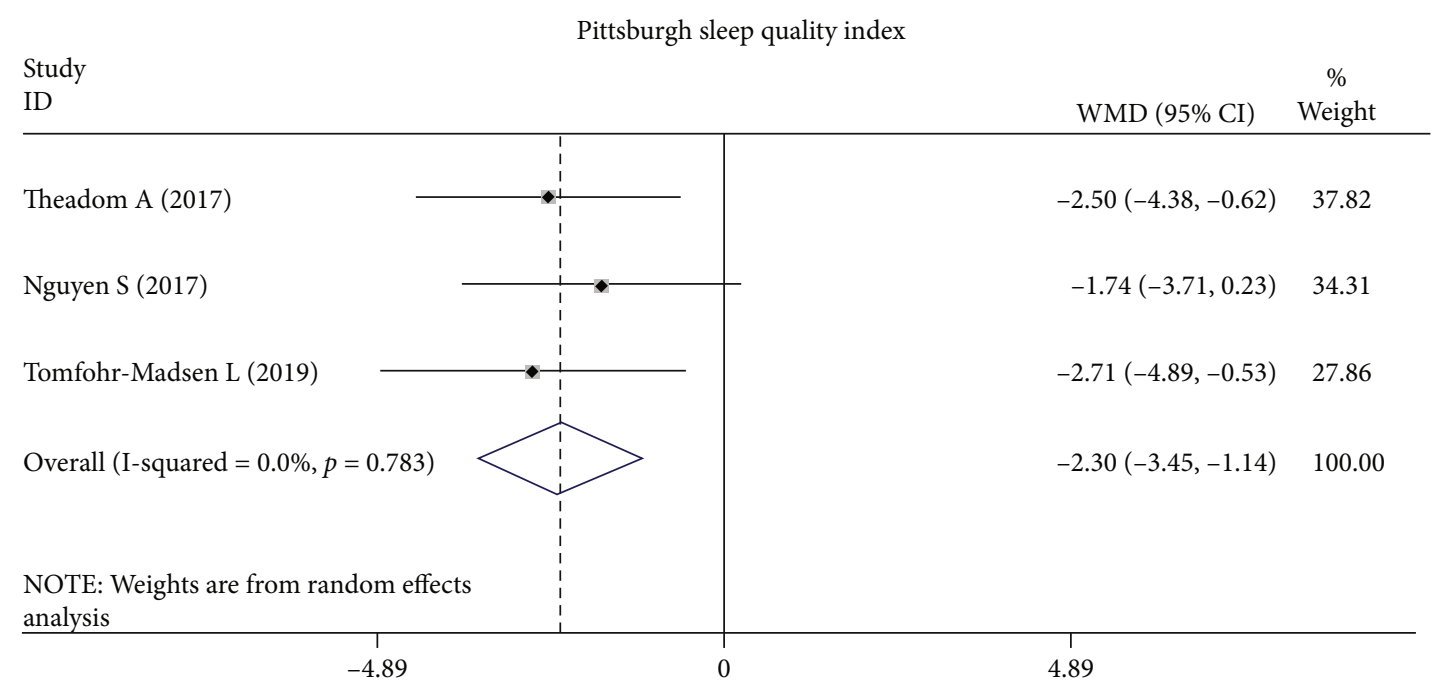

FIgURE 2: Differences in Pittsburgh Self-Reported Sleep Quality Index scores following CBT compared with other forms of interventions.

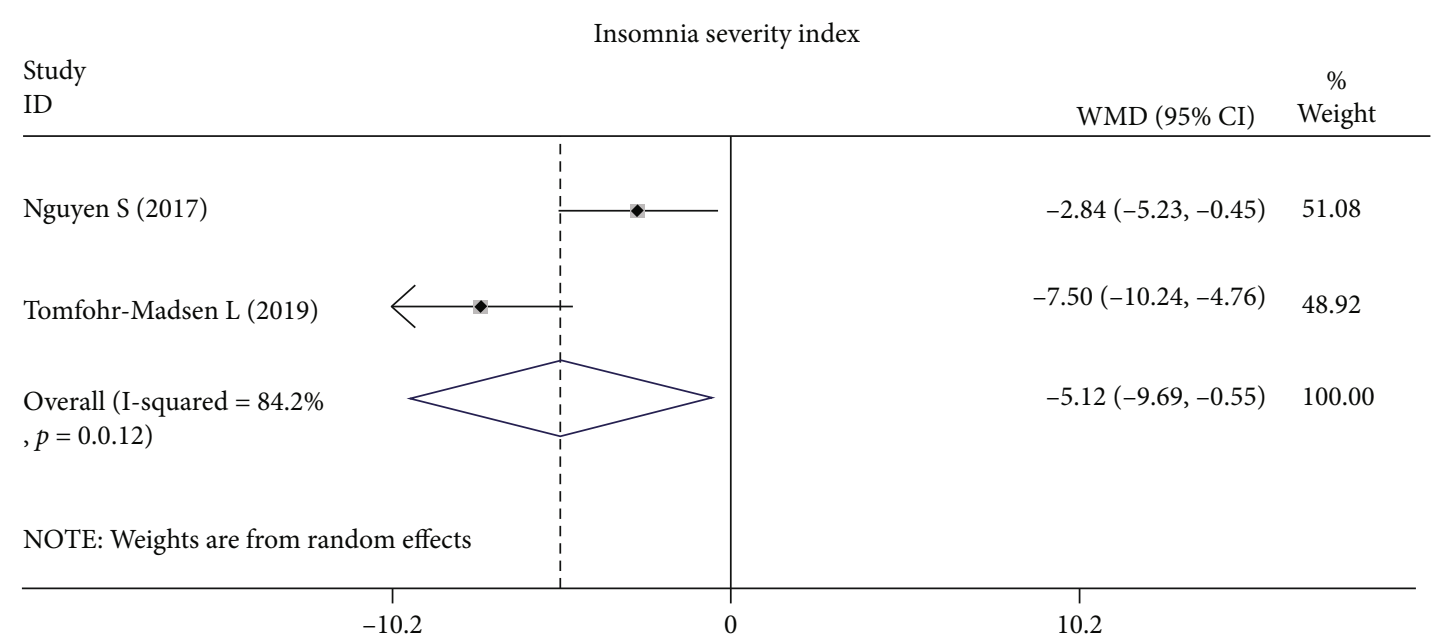

FIGURE 3: Differences in Insomnia Severity Index scores following CBT compared with other forms of interventions.

Ford and colleagues included 7 trials, comprising both clinical trials and single case studies, the present meta-analysis included only RCTs and was more concentrated on CBT and TBI. Last but not least, this was the first meta-analysis that synthesized evidence using quantitative methods, which provided a more objective estimate of the treatment effects. 


\section{Strengths and Limitations}

Although CBT is recommended for treating pain and sleep disorders in people after TBI, there has been no systematic review that revealed the therapeutic effects of CBT. This systematic review and meta-analysis is the first to show the therapeutic effect of CBT on posttraumatic pain, especially headache. Sleep quality and insomnia symptoms were also significantly improved. However, there are several limitations in this study. First, we had only a limited number of clinical trials that assessed the efficacy and safety of CBT among patients with TBI; thus, publication bias cannot be completely ruled out. Second, only half of the included studies evaluated quality of life, and none of the included studies assessed TBI-related restrictions to participation in daily life. Third, as the included studies reported outcomes by various methods, it was relatively difficult to derive a powerful synthesis of data evaluating CBT in groups of patients with TBI. Finally, although the meta-analysis showed that there were significant changes in sleep quality and insomnia, the clinical importance of the changes may be limited. Future multicenter, well-designed, large, population-based randomized control trials are needed.

\section{Conclusions}

CBT is relatively safe and is associated with significant improvements in self-reported sleep quality among patients with TBI, while limited evidence has shown that pain cannot be significantly improved by CBT. Nevertheless, interpretation of our results must be done cautiously considering the methodological drawbacks and poor quality of the data in the included trials. Future studies with more homogeneous, objective assessments are needed to determine whether CBT can be used to improve long-term clinical endpoints among these patients in the real world.

\section{Conflicts of Interest}

The authors declare that they have no conflicts of interest.

\section{Authors' Contributions}

Yuwei Feng and Jianping Xia contributed equally to this work as co-first authors.

\section{Acknowledgments}

This study was supported by the Clinical Research Unit, Xinhua Hospital Affiliated to Shanghai Jiao Tong University School of Medicine (18JXO06); "Star of Jiaotong University" Plan, Medicine-Engineering Interdisciplinary Research Fund of Shanghai Jiaotong University (YG2019ZD23); Medical Key Specialized Program of Chongming District; China Disabled Persons' Federation Programme (No. CJFJRRB032019); and "Action Plan for Sustainable Development of Science and Technology Innovation" in Chongming District, Shanghai (CKY2019-13).

\section{Supplementary Materials}

Appendix S1: the search strategies for the databases. Appendix S2: results of GRADE criteria. (Supplementary Materials)

\section{References}

[1] J. A. Langlois, S. R. Kegler, J. A. Butler et al., "Traumatic brain injury-related hospital discharges. Results from a 14-state surveillance system, 1997," Morbidity and Mortality Weekly Report Surveillance Summaries (Washington, DC : 2002), vol. 52, no. 4, pp. 1-20, 2003.

[2] M. H. Wilson, "Traumatic brain injury: an underappreciated public health issue," The Lancet Public Health, vol. 1, no. 2, article e44, 2016.

[3] M. Majdan, D. Plancikova, A. Maas et al., "Years of life lost due to traumatic brain injury in Europe: a cross-sectional analysis of 16 countries," PLoS Medicine, vol. 14, no. 7, article e1002331, 2017.

[4] C. J. Murray and A. D. Lopez, "Alternative projections of mortality and disability by cause 1990-2020: Global Burden of Disease Study," Lancet (London, England), vol. 349, no. 9064, pp. 1498-1504, 1997.

[5] A. I. Maas, N. Stocchetti, and R. Bullock, "Moderate and severe traumatic brain injury in adults," The Lancet Neurology, vol. 7, no. 8, pp. 728-741, 2008.

[6] A. R. Rabinowitz and H. S. Levin, "Cognitive sequelae of traumatic brain injury," The Psychiatric clinics of North America, vol. 37, no. 1, pp. 1-11, 2014.

[7] J. H. Badhiwala, J. R. Wilson, and M. G. Fehlings, "Global burden of traumatic brain and spinal cord injury," The Lancet Neurology, vol. 18, no. 1, pp. 24-25, 2019.

[8] S. Khoury and R. Benavides, "Pain with traumatic brain injury and psychological disorders," Progress in NeuroPsychopharmacology \& Biological Psychiatry, vol. 87, Part B, pp. 224-233, 2018.

[9] G. Lavigne, S. Khoury, J. M. Chauny, and A. Desautels, "Pain and sleep in post-concussion/mild traumatic brain injury," Pain, vol. 156, Supplement 1, pp. S75-s85, 2015.

[10] C. Weyer Jamora, S. C. Schroeder, and R. M. Ruff, "Pain and mild traumatic brain injury: the implications of pain severity on emotional and cognitive functioning," Brain Injury, vol. 27, no. 10, pp. 1134-1140, 2013.

[11] R. Diaz-Arrastia, P. M. Kochanek, P. Bergold et al., "Pharmacotherapy of traumatic brain injury: state of the science and the road forward: report of the Department of Defense Neurotrauma Pharmacology Workgroup," Journal of Neurotrauma, vol. 31, no. 2, pp. 135-158, 2014.

[12] E. L. Oar, C. Johnco, and T. H. Ollendick, "Cognitive behavioral therapy for anxiety and depression in children and adolescents," The Psychiatric Clinics of North America, vol. 40, no. 4, pp. 661-674, 2017.

[13] L. Surley and D. Dagnan, "A review of the frequency and nature of adaptations to cognitive behavioural therapy for adults with intellectual disabilities," Journal of Applied Research in Intellectual Disabilities : JARID, vol. 32, no. 2, pp. 219-237, 2019.

[14] B. Waldron, L. M. Casserly, and C. O'Sullivan, "Cognitive behavioural therapy for depression and anxiety in adults with acquired brain injury: what works for whom?," Neuropsychological Rehabilitation, vol. 23, no. 1, pp. 64-101, 2013. 
[15] Z. Q. Liu, X. Zeng, and C. Y. Duan, "Neuropsychological rehabilitation and psychotherapy of adult traumatic brain injury patients with depression: a systematic review and meta-analysis," Journal of Neurosurgical Sciences, vol. 62, no. 1, pp. 24-35, 2018.

[16] M. Gallagher, H. J. McLeod, and T. M. McMillan, "A systematic review of recommended modifications of CBT for people with cognitive impairments following brain injury," Neuropsychological Rehabilitation, vol. 29, no. 1, pp. 1-21, 2019.

[17] T. P. Baardseth, S. B. Goldberg, B. T. Pace et al., "Cognitive-behavioral therapy versus other therapies: redux," Clinical Psychology Review, vol. 33, no. 3, pp. 395-405, 2013.

[18] D. M. Ehde, T. M. Dillworth, and J. A. Turner, "Cognitivebehavioral therapy for individuals with chronic pain: efficacy, innovations, and directions for research," The American Psychologist, vol. 69, no. 2, pp. 153-166, 2014.

[19] S. McMain, M. G. Newman, Z. V. Segal, and R. J. DeRubeis, "Cognitive behavioral therapy: current status and future research directions," Psychotherapy Research : Journal of the Society for Psychotherapy Research, vol. 25, no. 3, pp. 321329, 2015.

[20] A. Liberati, D. G. Altman, J. Tetzlaff et al., "The PRISMA statement for reporting systematic reviews and meta-analyses of studies that evaluate health care interventions: explanation and elaboration," Journal of Clinical Epidemiology, vol. 62, no. 10, pp. e1-34, 2009.

[21] J. P. Higgins, D. G. Altman, P. C. Gotzsche et al., "The Cochrane Collaboration's tool for assessing risk of bias in randomised trials," BMJ (Clinical Research ed), vol. 343, p. d5928, 2011.

[22] S. P. Hozo, B. Djulbegovic, and I. Hozo, "Estimating the mean and variance from the median, range, and the size of a sample," BMC Medical Research Methodology, vol. 5, no. 1, p. 13, 2005.

[23] H. Balshem, M. Helfand, H. J. Schünemann et al., "GRADE guidelines: 3. rating the quality of evidence," Journal of Clinical Epidemiology, vol. 64, no. 4, pp. 401-406, 2011.

[24] D. Kjeldgaard, H. B. Forchhammer, T. W. Teasdale, and R. H. Jensen, "Cognitive behavioural treatment for the chronic post-traumatic headache patient: a randomized controlled trial," The Journal of Headache and Pain, vol. 15, no. 1, p. 81, 2014.

[25] S. D. Potter, R. G. Brown, and S. Fleminger, "Randomised, waiting list controlled trial of cognitive-behavioural therapy for persistent postconcussional symptoms after predominantly mild-moderate traumatic brain injury," Journal of Neurology, Neurosurgery, and Psychiatry, vol. 87, no. 10, pp. 1075-1083, 2016.

[26] A. Theadom, S. Barker-Collo, K. Jones, M. Dudley, N. Vincent, and V. Feigin, "A pilot randomized controlled trial of on-line interventions to improve sleep quality in adults after mild or moderate traumatic brain injury," Clinical Rehabilitation, vol. 32, no. 5, pp. 619-629, 2018.

[27] B. Gurr and B. R. Coetzer, "The effectiveness of cognitivebehavioural therapy for post-traumatic headaches," Brain Injury, vol. 19, no. 7, pp. 481-491, 2005.

[28] L. Tomfohr-Madsen, J. W. Madsen, D. Bonneville et al., "A pilot randomized controlled trial of cognitive-behavioral therapy for insomnia in adolescents with persistent postconcussion symptoms," The Journal of Head Trauma Rehabilitation, vol. 35, no. 2, pp. E103-e112, 2020.
[29] M. C. Ouellet and C. M. Morin, "Efficacy of cognitivebehavioral therapy for insomnia associated with traumatic brain injury: a single-case experimental design," Archives of Physical Medicine and Rehabilitation, vol. 88, no. 12, pp. 1581-1592, 2007.

[30] M. C. Ouellet and C. M. Morin, "Cognitive behavioral therapy for insomnia associated with traumatic brain injury: a singlecase study ${ }^{1}$," Archives of Physical Medicine and Rehabilitation, vol. 85, no. 8, pp. 1298-1302, 2004.

[31] W. Lu, J. W. Krellman, and M. P. Dijkers, "Can cognitive behavioral therapy for insomnia also treat fatigue, pain, and mood symptoms in individuals with traumatic brain injury? - a multiple case report," NeuroRehabilitation, vol. 38, no. 1, pp. 59-69, 2016.

[32] S. Lah, N. L. Phillips, T. M. Palermo et al., "A feasibility and acceptability study of cognitive behavioural treatment for insomnia in adolescents with traumatic brain injury: A-B with follow up design, randomized baseline, and replication across participants," Neuropsychological Rehabilitation, vol. 31, no. 3, pp. 345-368, 2021.

[33] C. A. McCarty, D. F. Zatzick, L. A. Marcynyszyn et al., "Effect of collaborative care on persistent postconcussive symptoms in adolescents: a randomized clinical trial," JAMA Network Open, vol. 4, no. 2, article e210207, 2021.

[34] S. Nguyen, A. McKay, D. Wong et al., "Cognitive behavior therapy to treat sleep disturbance and fatigue after traumatic brain injury: a pilot randomized controlled trial," Archives of Physical Medicine and Rehabilitation, vol. 98, no. 8, pp. 1508-1517.e2, 2017.

[35] V. B. Baker, K. M. Eliasen, and N. K. Hack, "Lifestyle modifications as therapy for medication refractory posttraumatic headache (PTHA) in the military population of Okinawa," The Journal of Headache and Pain, vol. 19, no. 1, p. 113, 2018.

[36] F. S. Zollman, C. Cyborski, and S. A. Duraski, “Actigraphy for assessment of sleep in traumatic brain injury: case series, review of the literature and proposed criteria for use," Brain Injury, vol. 24, no. 5, pp. 748-754, 2010.

[37] N. Goossens, S. Rummens, L. Janssens, K. Caeyenberghs, and S. Brumagne, "Association between sensorimotor impairments and functional brain changes in patients with low back pain: a critical review," American Journal of Physical Medicine \& Rehabilitation, vol. 97, no. 3, pp. 200-211, 2018.

[38] S. Lucas, "Headache management in concussion and mild traumatic brain injury," $P M \& R$ : the Journal of Injury, Function, and Rehabilitation, vol. 3, 10 Supplement 2, pp. S406S412, 2011.

[39] J. L. Mathias and P. K. Alvaro, "Prevalence of sleep disturbances, disorders, and problems following traumatic brain injury: a meta-analysis," Sleep Medicine, vol. 13, no. 7, pp. 898-905, 2012.

[40] C. Duclos, M. Dumont, C. Arbour et al., "Parallel recovery of consciousness and sleep in acute traumatic brain injury," $\mathrm{Neu}$ rology, vol. 88, no. 3, pp. 268-275, 2017.

[41] J. L. Ponsford, D. L. Parcell, K. L. Sinclair, M. Roper, and S. M. W. Rajaratnam, "Changes in sleep patterns following traumatic brain injury: a controlled study," Neurorehabilitation and Neural Repair, vol. 27, no. 7, pp. 613-621, 2013.

[42] A. Theadom, M. Cropley, P. Parmar et al., "Sleep difficulties one year following mild traumatic brain injury in a population-based study," Sleep medicine, vol. 16, no. 8, pp. 926-932, 2015. 
[43] M. C. Ouellet, S. Beaulieu-Bonneau, and C. M. Morin, "Sleepwake disturbances after traumatic brain injury," The Lancet Neurology, vol. 14, no. 7, pp. 746-757, 2015.

[44] M. E. Ford, E. Groet, J. G. Daams, G. J. Geurtsen, C. A. M. van Bennekom, and E. J. W. van Someren, "Non-pharmacological treatment for insomnia following acquired brain injury: a systematic review," Sleep Medicine Reviews, vol. 50, p. 101255, 2020. 